\title{
Diga Logo Qual é o Seu Nome e Sua Ocupação! A Disciplina Do Corpo
}

\author{
Tell Me Your Name and Occupation! \\ The Body's Subject
}

\author{
Rosilene Beatriz Machado* \\ ORCID iD 0000-0002-9621-7380 \\ Cláudia Regina Flores ${ }^{* *}$ \\ ORCID iD 0000-0003-2351-5712
}

\begin{abstract}
Resumo
Este artigo intenta analisar como as funções do desenho cambiaram para um disciplinamento do corpo no âmbito escolar, imbricado à Revolução Industrial. Em outras palavras, como as práticas de desenho, imersas em processos de disciplinarização, abandonaram as finalidades e a configuração de seus diversos campos sociais de origem para incorporar-se e sujeitar-se às finalidades escolares. O que reforça a compreensão de que os saberes escolares são gerados em meio a práticas, experiências e questões que uma sociedade se impõe como verdades e normas sociais, políticas e culturais.
\end{abstract}

Palavras-chave: Desenho, Matemática, História, Disciplina.

\begin{abstract}
This article tries to analyze how the drawing functions to a discipline of the body in the school scope, imbricated to the industrial revolution. In other words, as drawing practices, immersed in disciplinary processes, abandoned the purposes and configuration of their various social fields of origin to incorporate and submit to school purposes. This reinforces the understanding that school knowledge is generated through practices, experiences, and issues that a society imposes as social, political and cultural truths and norms.
\end{abstract}

Keywords: Drawing, Mathematics, History, Discipline.

\footnotetext{
* Doutora em Educação Científica e Tecnológica pela Universidade Federal de Santa Catarina (UFSC). Professora do Departamento de Metodologia de Ensino, Centro de Ciências da Educação da Universidade Federal de Santa Catarina (UFSC), Florianópolis, Santa Catarina, Brasil. Endereço para correspondência: Campus Universitário Reitor João David Ferreira Lima, CED, Bloco D, sala 413, Trindade, Florianópolis, Santa Catarina, Brasil, CEP: 88040-900. E-mail: rosilene.machado@ufsc.br.

** Doutora em Educação - Ensino de Ciências e Matemática pela Universidade Federal de Santa Catarina (UFSC). Professora do Departamento de Metodologia de Ensino e do Programa de Pós-Graduação em Educação Científica e Tecnológica (PPGECT) da Universidade Federal de Santa Catarina (UFSC), Florianópolis, Santa Catarina, Brasil. Pesquisadora do CNPq. Líder do grupo de pesquisa intitulado Grupo de Estudos Contemporâneos e Educação Matemática (GECEM). Endereço para correspondência: Campus Universitário Reitor João David Ferreira Lima, CED, Bloco D, sala 411, Trindade, Florianópolis, Santa Catarina, Brasil, CEP: 88040-900. E-mail: claudia.flores@ufsc.br.
} 


\section{Introdução}

Movimentando-nos de forma transversal pelos campos históricos (da Matemática, do Desenho, da Ciência, da Educação, da Educação Matemática, etc.), temos perguntado, especialmente, como práticas "podem chegar a engendrar domínios de saber que não somente fazem aparecer novos objetos, novos conceitos, novas técnicas, mas também fazem nascer formas totalmente novas de sujeitos e sujeitos de conhecimento" (FOUCAULT, 2013, p. 18). Como domínios de saber puderam formar-se a partir de práticas sociais; como determinadas práticas sociais, enfim, teriam adquirido o estatuto de conteúdo escolar. Isso tudo, a partir do pressuposto (sem presunção de prova, mas apenas de alargamento de potencialidades) de que investigar práticas sociais em âmbitos não escolares pode melhor esclarecer as características da vida escolar dessas mesmas práticas ${ }^{1}$; de que práticas de disciplinarização cultural (como as escolares) só são possíveis a partir de práticas de produção cultural (MIGUEL, 2010)².

Problematizando, então, como práticas sociais de desenhar teriam adquirido o estatuto de conteúdo escolar, nosso intuito em investigação recente foi perseguir os rastros da natureza histórica dos conteúdos escolares da disciplina de desenho ${ }^{3}$, mais especificamente, analisando como essas práticas, em sua historicidade, foram (re)significadas nos domínios da cartografia. Dessas análises, percebemos que grande parte dos conteúdos escolares dessa disciplina são provenientes dos tratados militares surgidos da "arte da fortificação" nos séculos XVI e XVII, já que foram da Academia Real Militar e da Academia dos GuardaMarinha que vieram muitos professores militares e livros didáticos para o ensino nos preparatórios e liceus provinciais ${ }^{4}$.

\footnotetext{
${ }^{1}$ Para uma maior compreensão acerca das perspectivas conceituais sob as quais nossos trabalhos em história(s) têm sido produzidos ver: Flores (2007); Machado (2016); Machado \& Flores (2016); Machado \& Flores (2016a). ${ }^{2}$ Cumpre dizer que há casos bastante específicos e pontuais de conteúdos ou disciplinas que emergem e disciplinarizam-se no interior da própria escola, tal como é o caso, por exemplo, da gramática francesa, analisado por Chervel (1990).

${ }^{3}$ Importante destacar que o problema de pesquisa colocado trata do desenho enquanto disciplina escolar, ou seja, não se pretende uma história de alguma modalidade específica de desenho (tal como desenho geométrico, perspectivo, descritivo, técnico, arquitetônico, industrial, artístico, dentre tantos outros).

${ }^{4}$ Com a chegada da corte portuguesa ao país em 1808, o ensino sofreu significativas mudanças através da Academia Real dos Guarda Marinha, que veio junto com a corte, e da criação da Academia Real Militar em 1811, que substituiu a Real Academia de Artilharia, Fortificação e Desenho. "A academia destinava-se ao ensino das ciências exatas e da engenharia em geral, no sentido mais amplo da sua época, formando não só oficiais de engenharia e de artilharia, como também geógrafos e topógrafos que pudessem trabalhar em minas, caminho, portos, canais, pontes, fontes e calçadas. Para essa formação, os alunos teriam um curso completo de ciências matemáticas e aprenderiam física, química, mineralogia, metalurgia e história natural, além do aprendizado das ciências militares. Os candidatos à Academia deveriam ter idade igual ou superior a 15 anos" (VALENTE, 2007, p. 93).
} 
Assim sendo, ao longo do século XIX, após a Independência do Brasil, o ensino de desenho foi gradativamente se deslocando ${ }^{5}$ do âmbito estrito da formação militar para a esfera pública, no bojo da criação das Escolas Normais (responsáveis por formar o professorado que atuaria na instrução primária); e dos Liceus Provinciais e do Colégio Pedro II, a partir de 1835 e 1837, respectivamente (ambos com vistas a garantir a formação de candidatos ao Ensino Superior). Os professores militares convocados para o ensino nessas novas instituições acabaram, assim, por difundir a escolarização técnico-militar desenvolvida nas Academias.

Os saberes em desenho e sua organização, veiculados pelos tratados militares, foram, portanto, transformados em conteúdos de ensino escolar a partir do século XIX. Saberes incorporados em livros didáticos e legislações do período ${ }^{6}$, organizados em torno da Geometria Plana e Espacial - da definição, construção, medida e divisão de ângulos, retas, triângulos, quadriláteros e demais polígonos regulares, irregulares, estrelados, bem como de círculos e circunferências; de problemas de inscrição e circunscrição; da construção de meia, terceira e quarta proporcionais; do estudo e construção de cônicas e espirais; da ampliação e redução de figuras; das medidas e equivalência de perímetro, área e volume; das definições, construção e medida de volume de figuras tridimensionais, tais como pirâmides, prismas, poliedros, esferas, cones e cilindros; da representação em perspectiva.

Além disso, a forma de exposição dos conteúdos através de problemas e suas resoluções, o uso de figuras a fim de auxiliar a compreensão das construções gráficas e o desenvolvimento de seções destinadas a explicar os principais instrumentos necessários (réguas, esquadros, lápis, compassos, etc.), são também heranças dos tratados militares; ainda que, ressalte-se, para atender as finalidades da Educação Básica, esses problemas tenham sido desvinculados de suas aplicações práticas no campo da fortificação.

O que se percebe, afinal, é que os livros didáticos de desenho tornaram-se uma espécie de receituário de construções geométricas, fundamentadas pela geometria euclidiana. Mantiveram-se, portanto, os saberes, mas os papéis que lhes foram designados cumprir no âmbito militar e no âmbito escolar configuraram-se de formas bastante diferentes. Se outrora as práticas de desenho imbricavam-se em práticas de fortificação visando garantir uma

\footnotetext{
${ }^{5}$ Em um complexo processo, tal como analisado em Machado (2016).

${ }^{6}$ Não nos estenderemos em uma análise pontual de livros didáticos ou legislações aqui. Nosso interesse é tão somente ressaltar a similaridade de seus conteúdos com aqueles oriundos dos tratados militares analisados em Machado (2016). Para atestar isso e para uma análise detalhada de diferentes obras escolares de desenho publicadas ao longo dos séculos XIX e XX, ver, especialmente, (...), assim como outros que igualmente apresentam análises desse tipo: Trinchão (2008), Dória (2004), Silva (2004), Zuin (2001).
} 
disciplina do espaço, agora elas têm a incumbência de assegurar um novo tipo de disciplinamento... É esse novo tipo de disciplinamento que se pretende analisar a seguir.

\section{Da disciplina do corpo}

Mesmo que em uma pertença disciplinar flutuante (ora cadeira isolada, ora instrumentalizador de outras disciplinas), desde as primeiras investidas na construção de um sistema de ensino público organizado no Brasil (esboçadas, efetivamente, após a Independência do país), os saberes em desenho estiveram fortemente presentes tanto no Ensino Primário e Secundário como também nas Escolas Normais. No Colégio Pedro II, por exemplo, o desenho figurou desde sua primeira organização curricular, em todos os níveis. Por vezes, assumiu a nomenclatura de Desenho; por outras, esteve articulado à disciplina de Desenho Linear ou Geometria Descritiva; e por outras, também, esteve inserido nas disciplinas de Geometria e Trigonometria. No campo da Geometria, ainda, seus saberes foram constantemente redistribuídos a cada programa que se apresentava, tendo sido nomeados de variadas maneiras ao longo desse percurso - figuraram como estereometria, planimetria, geometria plana, geometria no espaço e também geometria especial ${ }^{7}$.

Pois bem. Se, de fato, o desenho obteve presença marcante nos currículos escolares nos primórdios de sua organização no ensino básico, há que se destacar, porém, que isso só foi possível porque seu conjunto de saberes servia bem às propostas educacionais colocadas como demandas políticas entre os séculos XIX e XX. Tais propostas estavam imbricadas ao desejo de integração do país em uma nova economia de mercado, à consolidação de um Estado Nacional $^{8}$; a um padrão de modernidade sustentado pela indústria e que se estabelecia por meio de um discurso liberal (refletido de países industrializados, instruídos e civilizados, especialmente França, Alemanha e Inglaterra) difusor de um potente enunciado ${ }^{9}$ : a instrução pública garantirá ao país ordem e progresso econômico-industrial! Tornava-se urgente, afinal,

\footnotetext{
${ }^{7}$ Ver Vechia \& Lorenz (1998). Nesse livro são apresentados na íntegra dezoito documentos que apontam os conteúdos programáticos ensinados na escola secundária brasileira de 1850 a 1951 . Dentre estes, quinze dizem respeito especificamente ao Colégio Pedro II e os outros três foram expedidos pelo Ministério da Educação para serem implementados em nível nacional.

${ }^{8}$ Os Estados Nacionais surgidos, principalmente, entre os séculos XVIII e XIX, foram constituídos a partir do processo de industrialização, com mecanismos de divisão do espaço geográfico internacional, estabelecendo-se uma nova configuração política e espacial. Buscava-se, ainda, a soberania política e militar dentro dos territórios e o nacionalismo passou a ser fortemente propagado através de vários meios, dentre os quais a educação.

${ }^{9} \mathrm{O}$ enunciado, assim como o entende Foucault, não é qualquer coisa dita (ou mostrada...); ele não é um ato cotidiano; mas um tipo muito especial de ato discursivo, aceito e sancionado numa rede discursiva, segundo uma ordem - seja em função de seu conteúdo de verdade, daquele que praticou a enunciação, ou de uma instituição que o acolhe (VEIGA-NETO, 2007, p. 94-95).
} 
educar as massas, deixando-as ajustáveis ao desenvolvimento econômico e preparando os trabalhadores para compreender as bases da sociedade industrial.

A consolidação, portanto, desse modelo escolar, colado à institucionalização da escola pública brasileira só pôde efetivar-se porque atrelado a um dispositivo técnico-industrial. Ou seja, "um conjunto decididamente heterogêneo que engloba discursos, instituições, organizações arquitetônicas, decisões regulamentares, leis, medidas administrativas, enunciados científicos, proposições filosóficas, morais, filantrópicas” (FOUCAULT, 2010, p. 244).

Esse dispositivo da indústria, então, cumprindo uma função estratégica específica e inscrito em relações de poder e saber, fez do desenho, doravante, elemento chave de um potente enunciado do discurso técnico: o desenho é útil à economia das nações. Desenho e comércio; desenho e progresso; desenho e desenvolvimento; desenho e indústria; desenho e técnica. O ensino de desenho fazia-se essencial para a salvação das nações de seu atraso econômico e cultural em fins do século XIX ${ }^{10}$. Aí que, emaranhado nessa trama discursiva, parece ter adentrado os espaços escolares enquanto disciplina autônoma.

Mas há mais. Por outro lado, e amalgamado a tal dispositivo técnico-industrial, tal modelo escolar constituiu-se como um pujante dispositivo de Estado para o governamento da população. Não o governo, entendido como ações tomadas centralizadamente pelo Estado, mas sim um gouvernement, tal como utilizado por Foucault no conjunto de suas obras, indicando ação de governar, de dirigir condutas, isto é, "um conjunto de práxis, de saberes, de medidas, de instituições cujo objetivo é gerir, governar, controlar e orientar, num sentido que se supõe útil, os gestos e os pensamentos dos homens" (AGAMBEN, 2014, p. 37). Ações que formam, pois, sujeitos governáveis de fora, mas, também e principalmente, governáveis de dentro, na medida em que se configuram sujeitos autogovernados (com direitos e, sobretudo, deveres; um sujeito cidadão). Daí que à educação não se atribuía apenas o comprometimento com conhecimentos a ensinar, mas, primordialmente, a responsabilidade por condutas a inculcar.

Se a escola é "a instituição que mais ampla e precocemente se encarrega de 'capturar' os indivíduos", funcionando "como um lócus de acontecimentos acessível ao controle e à aplicação dos novos saberes e, principalmente, de preparar as massas a viverem num estado Governamentalizado" (VEIGA-NETO, 2000, p. 185) e se, como diz Agamben (2014), "os

${ }^{10}$ Tal é o caso da França, conforme aponta Renaud D’Enfert e Daniel Lagoutte (2004); de Portugal, conforme Lígia Penim (2011); também do Brasil, segundo Souza (2008); Nascimento (1994; 1999); Zuin (2001); Dória (2004); Trinchão (2008). 
dispositivos devem sempre implicar um processo de subjetivação, isto é, devem produzir o seu sujeito" (p. 37), era especialmente no meio escolar, por conseguinte, que o dispositivo técnico-industrial encontrava as condições de possibilidade para construção de seu sujeito: um sujeito escolar ajustado à sociedade disciplinar que se instituiu a partir do século XVIII e que descobriu no corpo um objeto e alvo de poder.

Corpo fabricado que agora se queria dócil: corpos adestrados que podem ser submetidos, utilizados, transformados e aperfeiçoados. "Um corpo que se manipula, se modela, se treina, que obedece, responde, se torna hábil ou cujas forças se multiplicam" (FOUCAULT, 1987, p. 117). O que se dá por meio de métodos - disciplinas, ou processos disciplinares - que realizam a sujeição constante das forças do corpo, impondo-lhe uma relação docilidade-utilidade:

\begin{abstract}
A disciplina fabrica assim corpos submissos e exercitados, 'corpos dóceis'. A disciplina aumenta as forças do corpo (em termos econômicos de utilidade) e diminui essas mesmas forças (em termos políticos de obediência). Em uma palavra: ela dissocia o poder do corpo; faz dele por um lado uma 'aptidão', uma 'capacidade' que ela procura aumentar; e inverte por outro lado a energia, a potência que poderia resultar disso, e faz dela uma relação de sujeição estrita. Se a exploração econômica separa a força e o produto do trabalho, digamos que a coerção disciplinar estabelece no corpo o elo coercitivo entre uma aptidão aumentada e uma dominação acentuada (FOUCAULT, 1987, p. 119).
\end{abstract}

Vê-se bem, então, que a escola figura como uma instituição disciplinar, já que estruturada através de disciplinas (no sentido de corpos de conhecimento organizados), mas também, e substancialmente, porque todo processo de disciplinarização envolve tanto organizar e classificar saberes, quanto domesticar os corpos e as vontades. Logo, a disciplina não se restringe à submissão de conhecimentos, mas age também sobre os corpos, com vistas à produção de um sujeito sujeitado, resultado de uma produção discursiva; constituído como objeto de saber e de dominação.

Isso se dá por uma distribuição dos indivíduos no espaço - de maneira que possam ser constantemente observados e controlados - através da clausura e do quadriculamento: "cada indivíduo no seu lugar; e em cada lugar um indivíduo" (Ibidem, p. 123); como também pelo controle de suas atividades através do ordenamento do tempo, com ritmos e atividades regularizadas; com a constituição, enfim, de um tempo integralmente útil ${ }^{11}$. O que não ocorre, note-se, por meio de alguma espécie de violência sobre os corpos, mas, antes, por relações de poder que visam seu adestramento. Assim, e portanto, é que a disciplina pode fabricar

\footnotetext{
11 As disciplinas, no sentido em que trata Foucault (1987), comportam uma série de outros elementos que as caracterizam, como, por exemplo, a instauração do panóptico enquanto modelo arquitetural. Para a argumentação que queremos desenvolver, entretanto, o que aqui destacamos são os pontos de maior interesse. Para uma compreensão aprofundada acerca do tema 'disciplinar' sugerimos a leitura de Foucault (1987).
} 
indivíduos:

ela é a técnica específica de um poder que toma os indivíduos ao mesmo tempo como objetos e como instrumentos de seu exercício. Não é um poder triunfante que, a partir de seu próprio excesso, pode-se fiar em seu superpoderio; é um poder modesto, desconfiado, que funciona a modo de uma economia calculada, mas permanente (FOUCAULT, 1987, p. 143).

Desejo de fabricação explicitado pelo filósofo Herbert Spencer, por exemplo, em sua obra Educação Intellectual, Moral e Physica, sucesso editorial por volta de 1860, tendo influenciado, segundo Souza (2008), educadores e intelectuais em todo o Ocidente. Como indicado no título, sua proposta era de uma educação intelectual - guiada pela ciência -, mas também, física e moral, sustentada pela crença do aperfeiçoamento do homem e da sociedade por meio da escola. "Ele antevia não apenas a formação de cidadãos racionais, mas também de cidadãos sensíveis, governados por si mesmos, portadores de critérios internos de julgamento sobre o bem e o mal, o certo e o errado - princípios ordenadores de uma vida civilizada" (p. 27). Sob essa mesma perspectiva, a educação (e a escola) deveria constituir-se assim dizia o jornal desterrense $O$ Novo Iris -, como "uma senhora doce e insinuante, inimiga da violência e do constrangimento, que ama obras por meio da persuasão, tendendo a tornar mais fácil a virtude" (O NOVO IRIS, n. 55, 20-9-1850, p.2, c.3, apud SCHAFASCHEK, 1997, p. 66, grifos nossos). Em outras palavras, era preciso que a educação servisse a cultivar virtudes, para bem conduzir as vontades, sujeitadas às leis.

As disciplinas (enquanto corpos organizados de conhecimentos), dessa forma, ao trabalharem para o adestramento e construção dos sujeitos escolares, configuraram-se, no processo de consolidação da instituição escolar, como potentes tecnologias (ou táticas) de governamento. Funcionaram (e ainda funcionam) como os meios pelos quais foi possível capturar, orientar, determinar, interceptar, instrumentalizar, moldar e normalizar os gestos, as condutas, as opiniões e os discursos dos sujeitos em determinada época.

Há que se destacar que tudo isso se dá sob um deslocamento das formas de governo de uma soberania sobre o território para uma soberania sobre a população: uma forma de governo que passava a atrelar a riqueza de um país menos à extensão de seu território do que à produtividade de sua população. Tratava-se da consolidação de uma governamentalidade liberal; liberalismo compreendido, com Foucault (2008), nem como uma fase histórica, tampouco como uma filosofia política ou um sistema econômico, mas como uma arte refinada de governar, uma racionalidade política; como prática de orientação das condutas, dos modos de ser e de agir dos indivíduos e das populações, respaldada pela ideia de governar menos para governar mais: 


\begin{abstract}
Ao querer naturalizar as relações sociais e econômicas ('a mão invisível de Deus'), o liberalismo deixa ao Estado, no máximo, a tarefa de ajustar socialmente o que já estaria impresso na natureza humana. Trata-se de uma lógica que entende a sociedade como um todo que deve ser harmônico pela combinação complementar de seus indivíduos, cada um funcionando como um átomo indivisível, centrado e estável, que é, em si mesmo e ao mesmo tempo, réu e juiz, ovelha e pastor. Assim, o liberalismo ocupa-se do 'governo da sociedade'; uma sociedade formada por sujeitos que são, cada um e ao mesmo tempo, objeto (governado de fora) e parceiro (sujeito autogovernado) do governo. Em outras palavras, um sujeito com deveres e direitos, um sujeito cidadão, um sujeito-parceiro (VEIGA-NETO, 2000, p. 184).
\end{abstract}

É nesse cenário, portanto, que se colocavam as condições para que a escola emergisse como uma instituição de destaque na formatação das massas; para que funcionasse, propriamente, como um dispositivo de ordenamento; "como uma máquina de governamentalização que consegue ser mais poderosa e ampla do que a prisão, o manicômio, o quartel, o hospital” (Idem, 2001, p. 109). Máquina cujo objetivo era enquadrar os sujeitos na sociedade, conduzir suas ações, que buscava, enfim, como temos mostrado, disciplinar os corpos. E que fez do desenho, enquanto mecanismo disciplinar, uma de suas tecnologias de governamento, de produção do sujeito escolar. Então, vejamos.

Inicialmente, cumpre dizer que "a aplicação do desenho nas artes da guerra, da fortificação, na engenharia e na arquitetura, tanto quanto nas artes mecânicas e nas ciências da vida, fez aumentar e consolidar a percepção da sua real necessidade social" (DIAS, 2009, p. 46). Ainda, por outro lado, servindo às exigências da ilustração das funções taxonômicas das ciências da natureza, o desenho havia ganhado "o estatuto de instrumento de comunicação e uma imagem de cientificidade conferida pelo próprio poder da comunidade científica" (Ibidem, p. 51). Além disso, por estarem historicamente amalgamados aos domínios da Matemática, particularmente da Geometria, e por estes serem conhecimentos tradicionalmente válidos per se - enquanto disciplinadores da mente -, os saberes em desenho (destacadamente os geométricos) tenderam a consolidar-se também como necessários ao desenvolvimento do raciocínio e, por conseguinte, à ação científica moderna, ancorada fundamentalmente nas matemáticas.

Mas essas são nuances de superfície, por assim dizer. Interessa-nos agora adentrar suas camadas sedimentares e atentar para os modos como o desenho contribuiu, efetivamente, para a construção do sujeito escolar moderno. Ou seja, analisar os mecanismos de poder e as tecnologias educativas que instaurou e das quais se utilizou a fim de disciplinar tal sujeito.

\title{
3 Do código disciplinar do desenho
}

É limitador pensar que o desenho se configurou em um mecanismo de poder apenas 
por constituir uma linguagem técnica fundamental aos preceitos industriais. Se figurou tanto como tecnologia de governamento do Estado, quanto, necessariamente, como tecnologia de governamento do sujeito, é porque desenhar exigia atenção, precisão, rigor e controle tanto da visão quanto da mão:

Na sua matriz geométrica, o desenho dispunha desses mecanismos disciplinares que, através dos exercícios de ajustamento e de coordenação entre a mão e a visão, desenvolviam a razão, mas também a vontade e atenção, modelando os modos de conduta do sujeito escolar. Pelos efeitos da ação disciplinadora dos saberes escolares sobre o indivíduo e indiretamente sobre a população, a escola assegurava o seu próprio poder de legitimação social (DIAS, 2009, p. 62).

Ora, as táticas de disciplinamento, como indica Foucault (1987), dão-se por duas relações fundamentais. Primeiro, por uma correlação entre o corpo e os gestos:

No bom emprego do corpo, que permite um bom emprego do tempo, nada deve ficar ocioso ou inútil: tudo deve ser chamado a formar o suporte do ato requerido. Um corpo bem disciplinado forma o contexto de realização do mínimo gesto. Uma boa caligrafia, por exemplo, supõe uma ginástica - uma rotina cujo rigoroso código abrange o corpo por inteiro, da ponta do pé à extremidade do indicador. (...) Um corpo disciplinado é a base de um gesto eficiente (p. 120).

Depois, também, por uma articulação corpo-objeto. A disciplina é definidora de cada uma das relações que o corpo deve manter com o objeto que manipula, estabelecendo cuidado e engrenagem entre um e outro:

Leve a arma à frente. Em três tempos. Levanta-se o fuzil com a mão direita, aproximando-o do corpo para mantê-lo perpendicularmente em frente ao joelho direito, a ponta do cano à altura do olho, apanhando-o batendo com a mão esquerda, o braço esticado colado ao corpo à altura do cinturão. No segundo, traz-se o fuzil com a mão esquerda diante de si, o cano para dentro entre os dois olhos, a prumo, a mão direita o apanha pelo punho, com o braço esticado, o guarda-mato apoiado sobre o primeiro dedo, a mão esquerda à altura da alça de mira, o polegar estendido ao longo do cano contra a soleira. No terceiro, a mão esquerda deixa o fuzil e cai ao longo da coxa, a mão direita o eleva, com o fecho para fora e em frente ao peito, com o braço direito meio esticado, o cotovelo colado ao corpo, o polegar estendido contra o fecho, apoiado ao primeiro parafuso, o cão apoiado sobre o primeiro dedo, o cano a prumo (FOUCAULT, 1987, p. 130).

Uma vez que essas duas relações - corpo-gesto e corpo-objeto - eram eximiamente mobilizadas pelas práticas de desenhar (o desenho de letras, inclusive, fazia parte do rol de conteúdos atribuídos à disciplina), o desenho tornava-se um efetivo e poderoso instrumento de disciplinamento. Desenhar requeria uma rigorosa ginástica, desde o momento de preparo dos materiais até à correta postura necessária para proceder aos seus traçados. O que exigia, ademais, a constituição de um rebuscado complexo corpo-instrumento, tal como pode ser percebido nas instruções oferecidas por Manoel de Azevedo Fortes, em seu tratado $O$ Engenheiro Português (1728):

Para dessenhar he necessatio huma meza firme, e liza, e sendo a planta grande, que naõ caiba na meza se deve por o papel, de sorte que o Dessenhador lhe naõ encoste o peito quando dessenha; e porque tambem naõ póde deixar de encostar o peito, se 
procurará hum sarrafo de madeira do comprimento da meza, com dous chapuzes, e dous parafuzos, para o Dessenhador poder encostar o peito, sem offender o papel, que passa por entre o sarrafo, e a meza (FORTES, 1728, p. 421).

Ou, citando outro exemplo, nas orientações mais recentes de José de Arruda Penteado, no livro didático Curso de Desenho $-3^{a}$ e $4^{a}$ séries ginasiais (1960), que assim adverte quanto ao material para o desenho geométrico:

Normas gerais. - Os alunos devem, antes de mais nada, utilizar seus instrumentos com o máximo cuidado, zêlo e atenção. Uma vez concluído um desenho, os instrumentos que foram utilizados devem ser limpados cuidadosamente, conforme as características próprias de cada um (...) Em seguida devem ser guardados com as devidas cautelas.

A) Traçado a lápis

\section{RÉGUA}

É o instrumento muito comum, básico, e de uso generalizado para o traçado de retas (fig. 2). Consiste numa peça direita, geralmente de madeira, ou de celulóide ou de galalite, graduada em centímetros. (...) O traçado correto e rigoroso de retas exige uma régua perfeita com graduação bem clara dos milímetros e centímetros.

Cuidados. - A régua deve ter os bordos perfeitamente alinhados, inteiramente desempenada, para evitar imperfeições no traçado. (...) Outra recomendação: não cortar papel apoiando material cortante ao bordo da régua.

A régua pode conservar-se, em casa, ou na sala ambiente de Desenho, verticalmente pendurada a apoiada sôbre superfície plana.

Normas práticas para seu emprêgo. - Para traçar uma reta, por exemplo, a lápis, depois de colocada (figs. 4 e 5) a régua na superfície que deverá ser ocupada, devemos considerar as seguintes normas práticas:

a) assentar firmemente a régua no espaço desejado e não deixa-la escorregar;

b) puxar o lápis, fig. 4, nunca empurra-lo;

c) manter a mina do lápis sempre na mesma posição, junto ao bôrdo da régua;

d) não empregar para desenhar o bôrdo chanfrado da régua graduada;

e) completar todo o traço da reta de uma só vez, sem paradas desnecessárias, fig. 5. Nessa ocasião, procurar manter a mina sempre com a mesma espessura durante todo o traçado.

Não esquecer, finalmente, que a posição do desenhista deve ser tal que possa observar, constantemente, o traçado que se está fazendo, fig. 6. (PENTEADO, 1960, p. 17; 19, grifos itálicos meus).
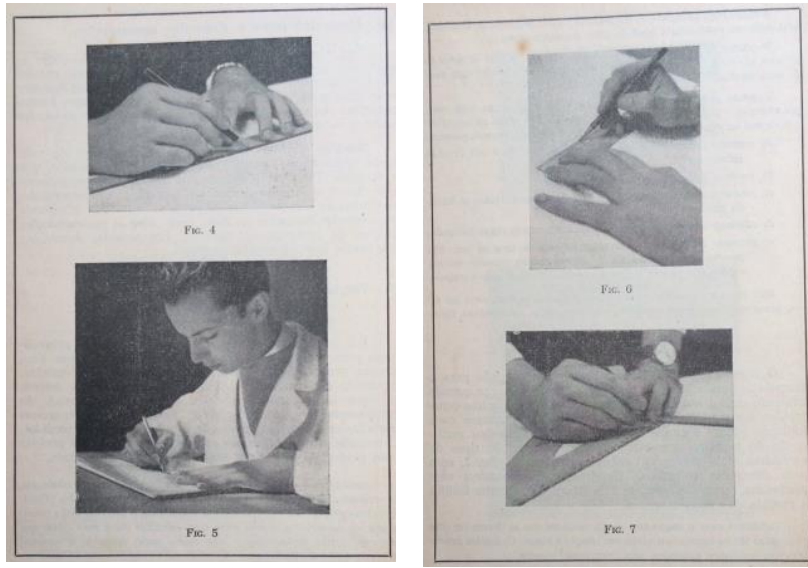

Figura 1 - Figuras indicadas por José de Arruda Penteado Fonte: PENTEADO (1960, p. 19) 
Percebe-se aí uma imposição entre os gestos e a atitude corpórea global, colocada como condição de eficácia e perfeição. E percebe-se, também, uma codificação instrumental do corpo, donde os gestos são decompostos em duas séries paralelas: a dos elementos corporais e a dos elementos dos objetos manipulados; as quais são correlacionadas e ordenadas para que se consiga um traçado correto e rigoroso:

\begin{abstract}
Estamos inteiramente longe daquelas formas de sujeição que só pediam ao corpo sinais ou produtos, formas de expressão ou o resultado de um trabalho. A regulamentação imposta pelo poder é ao mesmo tempo a lei de construção da operação. E assim aparece esse caráter do poder disciplinar: tem uma função menos de retirada que de síntese, menos de extorsão do produto que de laço coercitivo com o aparelho de produção (FOUCAULT, 1987, p. 131).
\end{abstract}

Os materiais, os gestos, a postura, enfim, todo o aparato concernente a um bem fazer da disciplina de desenho, funcionaram como tecnologias de controle, contribuindo à produção de um sujeito que fosse capaz de reunir o caráter persistente forjado no exercício da cópia, o espírito crítico e minucioso exercitado na observação e no cálculo mental, as dimensões, enfim, próprias de um pensamento experimental ou científico forjado no desenho, que a escola, enquanto lugar de formação colocava ao seu dispor como instrumento disciplinador dos sentidos e instrumento de governo de si mesmo (Ó, 2003). Tecnologias que, na forma do traço, infundiam uma verdade somatizada no dócil corpo do estudante, resultado do exercício sobre um corpo de desenho igualmente normalizado. Nesses interstícios em que a firmeza e a justeza do gesto foram sentidas como necessárias à construção do cidadão e da cidadania, um corpo docilmente desenhador seria, portanto, um corpo fabricado nos moldes educacionais, subjetivado pelas tecnologias que o investiram como sujeito capaz de uma conduta eficaz e ordenada, logo, econômica.

Por fim, interessante destacar que também pelas principais propostas de método de ensino, ou didáticas do desenho, quando de sua inserção no quadro da instrução pública nos séculos XIX e XX, circulou o enunciado acerca de seu poder disciplinador. Em Comenius, por exemplo, vê-se que a regra básica para o ensino dessa disciplina estava na prática da cópia de modelos. Os exercícios práticos é que deveriam ser exaltados, uma vez que só a prática faz $o$ artífice. $\mathrm{O}$ método consistia, inicialmente, no preparo de modelos perfeitos destinados à cópia; depois, à estipulação de regras de orientação; seguidos de outros exemplos semelhantes para imitação; então, obras de autores consagrados deveriam ser examinadas e relacionadas com os modelos e regras aprendidos, para, somente após a execução sistemática desse tipo de exercício, ser possível "avaliar com facilidade as invenções próprias e alheias, bem como sua elegância" (COMENIUS, 2002, p. 252). 
Rousseau, outro conhecido teórico da educação, igualmente defendia o ensino de desenho pela repetição e imitação de cópias, mas tomando a natureza como base. O objetivo não era propriamente a arte, mas "tornar seu olho [o da criança] justo e sua mão flexível", não tendo importância "que ela saiba tal ou qual exercício, desde que adquira a perspicácia do sentido e os bons hábitos do corpo que se ganham com o exercício" (ROUSSEAU, 1992, p. 145, grifos nossos). Com isso, a criança adquiriria um "golpe de vista mais preciso, uma mão mais segura, o conhecimento das verdadeiras relações de formas e tamanhos que existem entre os animais, as plantas, os corpos naturais e uma rápida experiência do jogo da perspectiva" (Ibidem, p. 145, grifos nossos). E então, quando "brinca com um arco, exercita o olho e o braço na precisão: quando chicoteia um pião aumenta sua força servindo-se dela" (Ibidem, p. 149).

Pode-se citar, ainda, Pestalozzi ${ }^{12}$, autor que valorizava a impressão sensorial como fundamento da instrução e para quem "o desenho é a capacidade de representar e reproduzir fielmente, pela observação de um objeto e por meio de tais linhas, o esboço deste objeto e personagens interiores que ele detém" (PESTALOZZI, 1889, p. 161, tradução nossa). Para Pestalozzi, o ensino de desenho também deveria dar-se com base em repetições exaustivas da cópia ou imitação de objetos em uma ideia de contínuo progresso, até que se adquirisse a habilidade perfeita, a fim de tornar o pensamento claro e preciso e exercitar a criança na grandeza da observação.

Tudo isso para destacar, enfim, que em todos esses discursos é a defesa da prática de repetição, do exercício da observação e do traçado sistemático que é ressaltada; que permitirá, portanto, educar o olho, disciplinar a mente e a mão.

\section{Para fechar}

É assim que as funções do desenho cambiaram de um disciplinamento do espaço, no âmbito militar (imbricado à arte da guerra), para um disciplinamento do corpo, no âmbito

\footnotetext{
${ }^{12}$ Embora, com Foucault (2009), não nos interessemos por quem, efetivamente, tenham sido tais teóricos, mas tão somente pelos enunciados e posições de sujeito que assumiram, trazemos, a título de informação ao leitor, breves comentários sobre os referidos autores: John Amos Comenius (1592-1670), um dos primeiros defensores de uma educação prática e universal, tal como exposto em sua obra principal Didática Magna (1657), é considerado o 'pai da educação moderna'; Jean-Jacques Rousseau (1712-1778) é considerado um dos principais filósofos iluministas e precursor do romantismo. Entende que as instituições educativas são corruptivas ao homem, tirando-lhe a liberdade. Assim, a fim de criar um homem e sociedade novos seria preciso educar a criança de acordo com a natureza, desenvolvendo progressivamente seus sentidos e a razão com vistas à liberdade e à capacidade de julgar; Johann Heinrich Pestalozzi (1746-1827) foi um pedagogo suíço e educador pioneiro da reforma educacional.
} 
escolar (imbricado à Revolução Industrial). Logo, as práticas de desenho, na medida em que foram passando por processos de disciplinarização, precisaram abandonar as finalidades e a configuração de seus diversos campos sociais de origem para incorporar-se e sujeitar-se às finalidades escolares. Finalidades que encontraram nos saberes em desenho os instrumentos de desenvolvimento e aperfeiçoamento da percepção, memória, razão, e também de controle do traço e rigor do ver - requisitos ambicionados pela escola e pela ordem industrial. Disso,

\begin{abstract}
Como fenômenos sociais, a institucionalização da escola pública e a escolarização do desenho mantém uma estreita e inequívoca relação. Se a 'gramática da escolaridade', ou seja, se 'o conjunto de aspectos organizacionais a que esteve subordinada a instrução' foi co-determinante no reconfigurar da identidade escolar do desenho, a inclusão deste na arena escolar acrescentou àquela (no processo de socialização e acomodação às normas escolares) novos instrumentos e mais valias pedagógicas. Produziram-se, nesse processo, um conjunto de instrumentos e práticas discursivas que deram ao desenho uma relativa estabilidade curricular (DIAS, 2009, p. 59).
\end{abstract}

Chegado a este ponto, pensamos que fica reforçada a percepção de que os saberes (sejam eles escolares ou não) são, de fato, gerados em meio a práticas, experiências e questões que uma sociedade se impõe como verdades e normas sociais, políticas e culturais. Resulta disso que o desenho só pode mesmo ser entendido como um conjunto de práticas significantes, inscrito em diversas tramas culturais, sendo produzido discursivamente em distintos tempos e espaços, e ele próprio produzindo, a cada vez, novos efeitos de verdade.

Então, deve um nome significar alguma coisa que não somente aquilo que dele se diz?

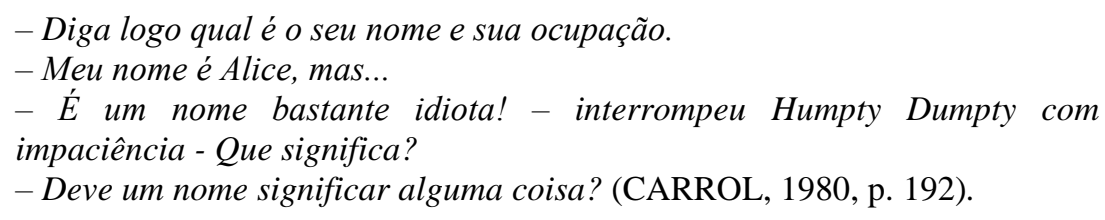

\title{
Referências
}

AGAMBEN, G. O amigo \& O que é um dispositivo? 1. ed., Chapecó, SC: Argos, 2014.

CARROLL, L. As aventuras de Alice no país das maravilhas, através do espelho \& o que Alice encontrou por lá. 3. ed. São Paulo: Summus, 1980.

CHERVEL, A. História das disciplinas escolares: reflexões sobre um campo de pesquisa. Tradução de: LOURO, G. L. Teoria e Educação, Porto Alegre, n. 2, p. 177-229, 1990.

COMENIUS, J. A. Didática Magna. Trad. Ivone Castilho Benedetti, 2. ed. São Paulo: Martins Fontes, 2002.

D'ENFERT, R.; LAGOUTTE, D. Un art pour tous. Le dessin à l'école de 1800 à nos jours. 1. ed. Lyon: INRP, 2004.

DIAS, M. dos A. F. Para uma genealogia da educação artística: História das disciplinas de Desenho, Trabalhos Manuais, Canto Coral e Educação pelo Teatro na escola primária portuguesa, do 
primeiro quartel do século XIX a meados do século XX. 2009. 734f. Tese (Doutorado em Estudos da Criança) - Universidade do Minho, Braga, Portugal, 2009.

DÓRIA, R. P. Entre o Belo e o Útil: manuais e práticas do ensino do desenho no Brasil do século XIX. 2004. 237f. Tese (Doutorado em Estruturas Ambientais Urbanas) - Universidade de São Paulo, São Paulo, SP, Brasil, 2004.

FLORES, C. R. Olhar, saber, representar: sobre a representação em perspectiva. 1. ed. São Paulo: Musa Editora, 2007.

FORTES, M. A. O engenheiro portuguez. 1. ed. Lisboa: Officinas Manoel Fernandes da Costa, 1728.

FOUCAULT, M. Vigiar e Punir: nascimento da prisão. 21. ed. Petrópolis: Vozes, 1987.

FOUCAULT, M. Segurança, território, população. 1. ed. São Paulo: Martins Fontes, 2008.

FOUCAULT, M. A Arqueologia do Saber. 7. ed. Rio de Janeiro: Forense Universitária, 2009.

FOUCAULT, M. Microfísica do Poder. MACHADO, R. (Org.). 28. ed. Rio de Janeiro: Edições Graal, 2010.

FOUCAULT, M. A verdade e as formas jurídicas. 4. ed. Rio de Janeiro: Nau, 2013.

MACHADO, R. B. Cartografia, Saber, Poder: Da emergência do desenho como disciplina escolar. 2016. 211f. Tese (Doutorado em Educação Científica e Tecnológica) - Universidade Federal de Santa Catarina, Florianópolis, SC, Brasil.

MACHADO, R. B.; FLORES, C. R. Entre práticas [historiográficas e de desenho]: um movimento metodológico de pesquisa. Zetetiké, Campinas, v. 24, n. 2, p. 237-248, 2016.

MACHADO, R. B.; FLORES, C. R. Considerações Intempestivas sobre um fazer História [da Educação Matemática]. In: REVEMAT, Florianópolis, v. 11, p. 149-161, 2016 a.

MIGUEL, A. Percursos Indisciplinares na Atividade de Pesquisa em História (da Educação Matemática): entre jogos discursivos como práticas e práticas como jogos discursivos. BOLEMA, Rio Claro, v. 23, n. 35A, abr. 2010.

NASCIMENTO, R. A. O Ensino do Desenho na Educação Brasileira: apogeu e decadência de uma disciplina escolar. 1994. 120f. Dissertação (Mestrado em Educação) - Faculdade de Filosofia e Ciências, Universidade Estadual Paulista, Marília, SP, Brasil, 1994.

NASCIMENTO, R. A. A função do desenho na educação. 1999. 216f. Tese (Doutorado em Educação) - Faculdade de Filosofia e Ciências, Universidade de São Paulo, Marília, SP, Brasil, 1999.

Ó, J. R. do. O governo de si mesmo. Modernidade Pedagógica e Encenações Disciplinares do Aluno Liceal (último quartel do século XIX- Meados do século XX). 1. ed. Lisboa: EDUCA, 2003.

PENIM, L. A alma e o engenho do currículo: história das disciplinas de Português e de Desenho no ensino secundário do último quartel do século XIX a meados do século XX. 1. ed. Lisboa: FCG, 2011.

PENTEADO, J. A. Curso de Desenho para a terceira e quarta séries ginasiais. 2. ed. São Paulo: Companhia Editora Nacional, 1960.

PESTALOZZI, J. H. Cómo Geetrudis enseña a sus hijos: fines y métodos de la éducacion del Pueblo. Cartas dirigidas a Gésser. Tradução José Tadeo Sepúlveda (versão chilena), 1889. 
ROUSSEAU, J. J. Emilio ou da Educação. Rio de Janeiro: Bertrand Brasil S.A, 1992.

SCHAFASCHEK, R. Educar para civilizar e instruir para progredir: análise de artigos divulgados pelos jornais do Desterro na década de 1850. 1997. 154f. Dissertação (Mestrado em Educação) Universidade Federal de Santa Catarina, Florianópolis, SC, Brasil, 1997.

SILVA, M. D. G. da. Os livros didáticos de desenho nos ginásios oficiais de São Paulo entre 19511961. 2004. 127f. Dissertação (Mestrado em Educação) - Pontifícia Universidade Católica, São Paulo, SP, Brasil, 2004.

SOUZA, R. F. História da organização do trabalho escolar e do currículo no século XX: (ensino primário e secundário no Brasil). 1. ed. São Paulo: Cortez, 2008.

TRINCHÃO, G. M. C. O desenho como objeto de ensino: história de uma disciplina a partir dos livros didáticos luso-brasileiros oitocentistas. 2008. 496 f. Tese (Doutorado em Educação) Universidade do Vale do Rio Sinos, São Leopoldo, RS, Brasil, 2008.

VALENTE, W. R. Uma história da matemática escolar no Brasil: 1730-1930. 2. ed. São Paulo: Annablume, 2007.

VECHIA, A; LORENZ, K. M. (Orgs.). Programa de ensino da escola secundária brasileira: 18501951 [Teaching programs of the Brazilian secondary school: 1850-1951]. Curitiba, Brasil: Autores, 1998.

VEIGA-NETO, A. Educação e governamentalidade neoliberal: novos dispositivos, novas subjetividades. In: PORTOCARRERO, V.; CASTELO BRANCO, G. (Org.). Retratos de Foucault. Rio de Janeiro: NAU, 2000. p. 179-217.

VEIGA-NETO, A. Foucault e a Educação. 2. ed. Belo Horizonte: Autêntica, 2007.

ZUIN, E. S. L. Da régua e do compasso: as construções geométricas como um saber escolar no Brasil. 2001. 211f. Dissertação (Mestrado em Educação) - Faculdade de Educação, Universidade Federal de Minas Gerais, Belo Horizonte, MG, Brasil, 2001. 